EDITORIAL

\title{
Improving the Chances of Manuscript Acceptance: How to Address Peer Reviewers' Comments
}

\author{
Mary H H Ensom
}

$\mathrm{I}^{\mathrm{t}}$

f you are one of the hundreds of authors who have submitted a manuscript to the CJHP over the past few years, you will have received one or more decision letters in one or more of the following categories: (1) "reject (at the pre-review stage)", (2) "revise and re-review (at the pre-review stage)", (3) "accept revisions needed" (further subcategorized as "accept after revisions" or "request major revisions"), (4) "reject (after peer review)", or (5) "final accept".

Unless your submission was a letter to the editor or an article such as a Practice Spotlight or a Point Counterpoint piece on which you were already working with an associate editor, it is unlikely that your initial decision letter fell into category 5. Thus, your decision letters have probably included comments and suggestions requiring your attention. The purpose of this editorial is to provide authors who have received such letters with tips on how to improve the chances that their manuscripts will be accepted by the CJHP and, more specifically, how to address the comments of both the peer reviewers and the assigned associate editor. These tips are based on decades of my own personal experience as an author, peer reviewer, associate editor, and editor of the CJHP, as well as my experiences as an author, peer reviewer, and editorial board member with numerous other international biomedical journals.

When you submit a manuscript to the CJHP, it undergoes pre-review by the editor and/or an associate editor before it is sent out to external peer reviewers. Consequently, if you receive a decision letter at the pre-review stage (i.e., category 1 or 2), it will typically contain comments from only the editor and/or associate editor.

A category 1 letter (reject) most likely means that your manuscript does not fall within the scope of the CJHP, which has the stated mission of being "a respected international publication while serving as the major venue for dissemination of information related to patient-centred pharmacy practice in hospitals and related health care settings in Canada." However, just because your manuscript is deemed unsuitable for the CJHP does not mean that it will not find a home in another journal. If in doubt, do not hesitate to discuss the article with the editor of your selected target journal in advance. As an author, I often send an e-mail inquiry to a prospective journal editor

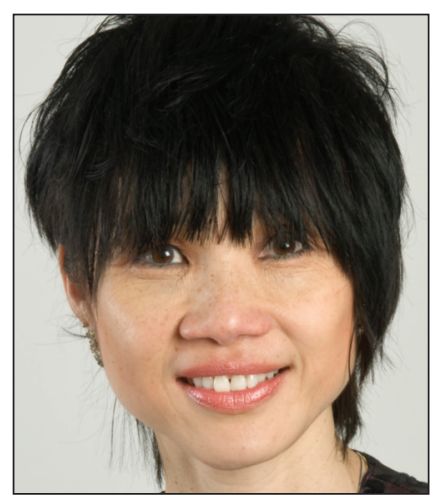
to ascertain that particular journal's interest in receiving my manuscript. Similarly, we at CJHP also receive and welcome presubmission e-mails from prospective authors.

Alternatively, your manuscript might be rejected at the pre-review stage because it contains fatal methodological flaws that the editors believe to be unsalvageable. Again, you still may be able to find a home for your paper elsewhere, possibly even in the letters section of CJHP (for which submissions typically do not undergo external peer review), if it has something to offer and if you incorporate the editors' suggestions for improvement.

A poorly written paper may fall under category 1 or 2 , depending on how serious the flaws are and how "redeemable" the paper is. In a category 2 letter (revise and re-review), we usually ask the authors of a paper with obvious deficiencies to revise it before we will send it out to reviewers. Remember, thoughwe are on your side. In our desire to publish the best possible articles in our Journal, we strive to provide you with comments that will allow you to strengthen your paper to meet the Journal's standards before it goes out to reviewers. A word to the wise is to resubmit promptly and to supply additional information and/or requested revisions in a point-by-point fashion.

If your paper passes the pre-review stage, the editors who have examined it believe that it has sufficient merit to be sent 
out for formal review by individuals with expertise in the subject area of the paper. Congratulations if your paper reaches this step. Although acceptance rates in the CJHP vary according to the type of article, more than $50 \%$ of articles that are sent out for review are eventually accepted for publication in the Journal. ${ }^{1}$ After the reviewers have returned their feedback, the most likely outcome is a category 3 decision letter. Typically, this type of decision letter includes comments from at least 2 peer reviewers and the assigned associate editor. In their responses to the decision letter, we expect authors to exemplify the same attributes we seek in a good peer reviewer; these include, but are not limited to, promptness, organization, tactfulness, constructiveness, objectivity, specificity, precision, and completeness. ${ }^{2}$

After receiving a category 3 decision letter and accompanying reviews, you should be prompt in resubmitting a revised version of the paper. A delay may be construed as a lack of enthusiasm on your part for publishing your paper. If you need more time, then you should notify the Journal immediately, rather than after the deadline for resubmission has passed. Your resubmission should be well organized and should include a point-by-point response to the reviewers' comments, indicating your revisions in the text by page and line numbers. We request that you submit both a marked-up version (with revisions highlighted or indicated with tracked changes) and a "clean" version of the manuscript. It is okay to disagree with the reviewers, but you should state your rebuttal tactfully; if you disagree, do so respectfully. For instance, you might begin your rebuttal by saying, "We acknowledge the reviewer's point, but respectfully disagree for the following reasons." You should also provide constructive responses to the reviewers' comments. Even if you feel that the reviewer is wrong, you can provide your rebuttal in a constructive manner, with supporting evidence. Although you are not expected to incorporate every suggestion from every reviewer, you should respond to every single one of their comments in your point-by-point rebuttal letter. Of course, you will need to be objective, citing references and/or revising particular sections as requested. Speaking as an author, the reviewers' comments sometimes make me very angry (prompting me to ask, "Didn't they even read my paper?"). However, after taking time to simmer down, I usually realize that if something was unclear to the reviewer, it would likely be equally unclear to a future reader. At the end of the day, addressing the reviewers' comments (whether or not I am in agreement) has always helped me to strengthen my papers.

Be as specific, precise, and complete as possible in your response to reviewers. Make the reviewers' and editors' lives easier by considering all of the aforementioned attributes in your resubmission. ${ }^{2}$ Indeed, if you revise your manuscript exactly as advised in the decision letter, it will be difficult for the editors not to accept it. Sometimes, you will receive conflicting comments from the reviewers. If the associate editor has not provided direction on which approach or stance to take, feel free to contact the Journal (cdrake@cshp.ca), and we can put you in touch with the appropriate individual. Alternatively, in your response to reviewers, you can state your preferred approach (with justification) and defer to the editors to make the final decision.

Many resubmissions based on category 3 letters are not sent back to the original reviewers. Often, especially if you have heeded the advice in the original decision letter, your revised manuscript will be reviewed by only the associate editor to whom it is assigned. In cases where the resubmission does go back to the original (most often) or different (occasionally) reviewers, you should recognize that these readers will sometimes identify issues that were missed in the original submission. Although that may be aggravating to you, remember again that we are on your side and want to have the best possible papers published in our Journal.

Even if you receive a category 4 decision letter (reject after peer review), read the reviewers' comments carefully and use them to strengthen your paper for submission to another journal. At the same time, you must remember that pharmacy is a relatively small world, and a manuscript submitted to a different journal may end up in the hands of the same reviewer. In fact, this has happened on at least one occasion recently, with a paper being assigned to a CJHP associate editor who previously reviewed the same paper for another journal. However, to this person's surprise, the authors had ignored the painstakingly crafted comments supplied during the earlier review, and the submission to the CJHP was identical to the one that had been reviewed for (and ultimately rejected by) the other journal.

We keep track of the reasons why manuscripts are rejected, and the following are the most common reasons: has a fatal flaw in design and/or reporting (e.g., inappropriate methodology and/or analyses), lacks originality and/or contributes little new information to the literature, has low impact and/or minimal applicability to other sites, does not answer the stated research question, does not meet standard of practice for Canadian pharmacists, is poorly written (e.g., poor organization and/or clarity, inadequate description and interpretation of results), and does not conform to the journal's submission requirements.

Williams $s^{3}$ offered an excellent summary of how to respond to reviewers: "completely, politely, and with evidence." In addition, to echo DeMaria, ${ }^{4}$ the $C J H P$ values manuscripts "that are promptly submitted, with detailed replies to each of the issues raised and with the manuscript changes introduced in response to each issue well delineated in the rebuttal letter." But perhaps Peh and $\mathrm{Ng}^{5}$ said it best: "A request for revision should be viewed positively, as it means that there is a possibility that the manuscript may still be potentially publishable, provided that all the editor's and reviewers' comments are addressed." 
References

1. Ensom MHH. Facts and comparisons: journal updates and performance indicators [editorial]. Can J Hosp Pharm 2010;63(4):281-283.

2. Ensom MHH. The art and science of peerless peer review [abstract]. Can J Hosp Pharm 2007;60(Suppl 1):31-32.

3. Williams HC. How to reply to referees' comments when submitting manuscripts for publication. J Am Acad Dermatol 2004;51(1):79-83.

4. DeMaria A. Manuscript revision. J Am Coll Cardiol 2011;57(25): 2540-2541.

5. Peh WC, Ng KH. Dealing with returned manuscripts. Singapore Med J 2009;50(11):1050-1052.
Mary H H Ensom, PharmD, FASHP, FCCP, FCSHP, FCAHS, is Professor and Director, Doctor of Pharmacy Program, Faculty of Pharmaceutical Sciences, and Distinguished University Scholar, The University of British Columbia, and Clinical Pharmacy Specialist, Children's \& Women's Health Centre of British Columbia, Vancouver, British Columbia. She is also Editor of the CJHP.

\section{Address correspondence to:}

Dr Mary $\mathrm{H} \mathrm{H}$ Ensom

Department of Pharmacy (OB7)

Children's \& Women's Health Centre of British Columbia

4500 Oak Street

Vancouver BC V6B 6E4

e-mail: ensom@mail.ubc.ca

\section{Acknowledgements}

I would like to take this opportunity to express my sincerest appreciation to all the individuals who volunteer their time as associate editors and reviewers for the $C J H P$.

\section{ON THE FRONT COVER}

\section{Mount Seymour, British Columbia}

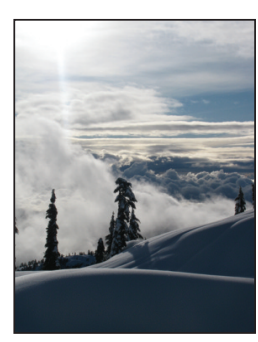

Mount Seymour is a favourite snowshoeing spot for photographer and CSHP member Sarah West and her husband, and it's just a short 20-minute drive from downtown Vancouver! In this photograph, the sweeping snowscapes at the first summit of Mount Seymour form a perfect foreground to the clouds sweeping over the city below. Although the sky was overcast in the city, the sun was shining up on the peaks. This photo was taken in January 2011 with a Canon Power Shot SX110 IS..

The CJHP would be pleased to consider photographs featuring Canadian scenery taken by CSHP members for use on the front cover of the journal. If you would like to submit a photograph, please send an electronic copy (minimum resolution $300 \mathrm{dpi}$ ) to Colleen Drake at cdrake@cshp.ca. 